\title{
Powder and Suspension for Suspension for Injection Dosage Form
}

National Cancer Institute

\section{Source}

National Cancer Institute. Powder and Suspension for Suspension for Injection Dosage

Form. NCl Thesaurus. Code C149805.

Sterile powder and sterile suspension, both of which contain active substance(s), intended for the preparation of a suspension for injection by dispersing the powder in the suspension. 